\title{
Determinants of Use of Modern Family Planning among Northern Nigerian Women: A Secondary Analysis of 2013 NDHS
}

\author{
Lawrence Ikeako1, Ngozi Joe-Ikechebelu², Basil Nwankwo ${ }^{3}$, Prince Onyemachi ${ }^{4}$, John Chikezie ${ }^{5}$, \\ Isaiah Abali6, Jane Anene ${ }^{7}$, Ebele Azuike ${ }^{8}$, Emmanuel Azuike ${ }^{2,9 *}$ \\ ${ }^{1}$ Department of Obstetrics and Gynaecology, Chukwuemeka Odumegwu Ojukwu University/University Teaching Hospital, \\ Awka, Nigeria \\ ${ }^{2}$ Department of Community Medicine, Chukwuemeka Odumegwu Ojukwu University/University Teaching Hospital, \\ Awka, Nigeria \\ ${ }^{3}$ Department of ENT, Chukwuemeka Odumegwu Ojukwu University Teaching Hospital, Awka, Nigeria \\ ${ }^{4}$ Department of Community Medicine, Abia State University, Uturu, Nigeria \\ ${ }^{5}$ Department of Internal Medicine, Abia State University, Uturu, Nigeria \\ ${ }^{6}$ Department of Surgery, Abia State University, Uturu, Nigeria \\ ${ }^{7}$ Department of Health, Anambra State Local Government Service Commission, Awka, Nigeria \\ ${ }^{8}$ Department of Nursing Sciences, College of Health Sciences, Nnamdi Azikiwe University, Awka, Nigeria \\ ${ }^{9}$ Foundation for Health and Development in Nigeria, Nnewi, Nigeria \\ Email: *emmanazuike@yahoo.com
}

How to cite this paper: Ikeako, L. Joe-Ikechebelu, N., Nwankwo, B., Onyemachi, P., Chikezie, J., Abali, I., Anene, J., Azuike, E. and Azuike, E. (2018) Determinants of Use of Modern Family Planning among Northern Nigerian Women: A Secondary Analysis of 2013 NDHS. Open Access Library Journal, 5: e4521. https://doi.org/10.4236/oalib.1104521

Received: March 19, 2018

Accepted: May 15, 2018

Published: May 18, 2018

Copyright $\odot 2018$ by authors and Open Access Library Inc.

This work is licensed under the Creative Commons Attribution International License (CC BY 4.0).

http://creativecommons.org/licenses/by/4.0/

cc) (i) Open Access

\begin{abstract}
Introduction: Family planning allows people to attain their desired number of children and determine the spacing of pregnancies. It is achieved through use of contraceptive methods and the treatment of infertility. The aim of this study was to determine various factors that influenced the uptake of modern family planning among women of reproductive age in Northern Nigeria. Methodology: The study used data obtained from Nigeria Demographic and Health Survey (NDHS) 2013. Factors considered were drawn from the dataset. Analysis was carried out using Stata version 12.1. Multivariate logistic regression analysis was used to determine relationship between various factors and use of modern family planning methods. Level of significance was set at 0.05. Results: The total number of participants in the study was 21,037 . The mean age of respondents was $29.0 \pm 7.1$ years. Only $5.3 \%$ of the participants were currently using modern family planning methods. The highest proportion of use was $14.3 \%$ in the Northcentral zone of Northern Nigeria, while the lowest was $2.38 \%$ in Northwest. Identified predictors of modern family planning use were: Having at least secondary education $(\mathrm{OR}=3.8,95 \% \mathrm{CI}$ : $3.3-4.4)$, being from the Northcentral ( $\mathrm{OR}=3.9,95 \%$ CI: $3.4-4.5)$, being 25 years old or
\end{abstract}


more $(\mathrm{OR}=1.7,95 \% \mathrm{CI}: 1.5-2.1)$ and being of urban residence $(\mathrm{OR}=2.0$, 95\% CI: 1.8 - 2.4). All factors were statistically significant $(\mathrm{P}<0.001)$. The highest predictor of modern family planning uptake was geopolitical zone, followed by education. Conclusion: Measures should be taken to increase female literacy especially in the Northeastern and Northwestern zones of Northern Nigeria, as this will most likely lead to improved uptake of modern family planning among the respondents.

\section{Subject Areas}

Numerical Mathematics, Partial Differential Equation

\section{Keywords}

Modern Family Planning, Northern Nigerian Women

\section{Introduction}

One of the key National Policy on Reproductive Health is to reduce maternal morbidity due to pregnancy and childbirth by $50 \%$. One of the strategic thrusts is the promotion of a healthy reproductive health lifestyle by process of providing appropriate knowledge to bring about appropriate behavioural change and improve participation in the use of reproductive health services [1]. According to the World Health Organisation (WHO), family planning allows people to attain their desired number of children and determine the spacing of pregnancies; it is achieved through use of contraceptive methods and the treatment of infertility [2]. According to WHO the advantages of family planning include (but not limited to): Preventing pregnancy-related health risks in women, reducing infant mortality, helping to prevent HIV/AIDS, empowering people and enhancing education, reducing adolescent pregnancies, slowing population growth, etc. [2].

The Demographic and Health survey classified methods of family planning into modern methods, traditional methods and folkloric methods [3]. Modern methods include: Female sterilization (tubal ligation, voluntary surgical contraception for women), male sterilization (vasectomy, voluntary surgical contraception for men), the contraceptive pill (oral contraceptives), intra-uterine contraceptive device (IUD), injectables (Depo-Provera) and implants (Norplant). Other modern methods include: female condom, male condom (prophylactic, rubber), diaphragm, contraceptive foam and contraceptive jelly, lactational amenorrhea method (LAM), emergency contraception, country-specific modern methods and other modern contraceptive methods respondents mentioned (including cervical cap, contraceptive sponge, and others). Traditional methods include: periodic abstinence (rhythm, calendar method), withdrawal (coitus interruptus) and country-specific traditional methods of proven effectiveness. Folkloric methods include: locally described methods and spiritual methods of unproven effectiveness, such as herbs, amulets, gris-gris, etc. [3]. 
Since modern family planning methods have been proven to be scientifically effective. It is important to identify factors affecting its use. Knowledge of these factors will help channel interventions in a direction that will improve their utilization. This study analysed data obtained by the 2013 Nigeria Demographic and Health Survey to determine correlates of use of modern family planning methods. The aim of the study was to determine the factors that influence use of modern family planning methods by women in the Northern region of Nigeria.

\section{Methodology}

The Demographic and Health Surveys (DHSs) are nationally-representative household surveys that provide data for a wide range of monitoring and impact evaluation indicators in the areas of population, health, and nutrition for low and middle income countries [3]. This study used Nigeria Demographic and Health Survey 2013 dataset. Ethical approval was obtained from the ethical committee of Chukwuemeka Odumegwu Ojukwu University Teaching Hospital, Awka. Only females of reproductive age (15 to 49 years) from the northern region of the country were included in the study. The women were 21,037 in number. Data was analysed using Stata data analysis software Version 12.1.

Some basic characteristics of the women were explored including: the geo-political zone they belong to, the age of the women, the highest educational level they attained, their place of residence (urban/rural), current method of family planning, current marital status. Frequencies and percentages were displayed in tables. Binomial logistic regression was used to establish the determinants of use of modern family planning among the women. The dependent variable was the current family method of the women. This variable was originally grouped into four possible outcomes: No family planning method, traditional method, folkloric method and modern method. But for the purpose of this study, this variable was re-coded into only two possible outcomes: Modern family planning method and others. The independent variables were: educational level, the geo-political zone the women belong to, age of the women, place of residence (urban/rural) and marital status of the women. Some of the independent variables which had more than two categories were re-coded into only two categories. The educational level was re-coded into two categories: minimum of secondary school and primary school or less. Geo-political zone was re-coded into two categories: North-Central and North-East/North-West. Age was re-coded into two categories: 25 years or more and 24 years or less. Marital status was re-coded into two categories: Currently married and others. The p-value was set at 0.05 meaning that any p-value that is less than 0.05 was considered statistically significant.

\section{Results}

Twenty one thousand, thirty seven women were involved in the study. The women were from all the three geo-political zones in the Northern region of the 
country. The North-west geopolitical zone had the highest proportion of participants (47.09\%) (Table 1).

Table 2 shows the age distribution of the respondents. The most common age group was the 25 to 29 years age group which made up $27.97 \%$ of all the respondents. The least represented age group was the $45-49$ years age group (3.10\%).

Table 3 shows the respondents' highest level of education. Only $3.31 \%$ of the respondents had tertiary education. Those that had no education made up $66.07 \%$ of the respondents. Among the respondents $16.49 \%$ had only primary education while $14.13 \%$ had secondary education.

Table 4 shows the current method of family planning the respondents were using. Modern method was being used by $5.33 \%$ of the respondents, while $0.89 \%$ of the respondents were using traditional method.

Table 5 shows the marital status of the women.

Table 6 shows the proportion of the women from each of the geo-political zones in the Northern region who use modern family planning methods.

Table 7 shows the odds ratios for the predictors of use of modern family planning methods. The women who had at least secondary education were 3.8 times more likely than those who had less than secondary education to use modern family planning methods. Women who were 25 years or more were 1.7 times more likely than those who were less than 25 years to use modern family planning methods. The women from the North central geo-political zone were almost four times more likely that those from the other 2 geo-political zones to use modern family planning. The women who lived in urban areas were twice more likely to use modern family planning methods than those who lived in the rural areas. All the above were statistically significant. Married women were 1.3 times more likely to use modern family planning than other women, but this was not statistically significant.

\section{Discussion}

The most common age group was the 25 - 29 years age group which made up $27.97 \%$ of all the respondents, while the least represented age group was the 45 49 years age group (3.10\%). More than half $(66.07 \%)$ of the 21,037 women who participated in the present study had no education. Majority of the women

Table 1. Distribution of the respondents according to geo-political zones of the Northern region of the country.

\begin{tabular}{ccc}
\hline Geo-political zone & Frequency & Percentage \\
\hline North Central & 4614 & 21.9 \\
North East & 6517 & 30.9 \\
North West & 9906 & 47.1 \\
Total & 21,037 & 100.0 \\
\hline
\end{tabular}


Table 2. Age distribution of the respondents (years).

\begin{tabular}{ccc}
\hline Age group (years) & Frequency & Percentage \\
\hline $15-19$ & 1206 & 5.7 \\
$20-24$ & 4512 & 21.5 \\
$25-29$ & 5885 & 27.9 \\
$30-34$ & 4215 & 20.0 \\
$35-39$ & 3037 & 14.4 \\
$40-44$ & 1529 & 7.3 \\
$45-49$ & 653 & 3.1 \\
Total & 21,037 & 100.0 \\
\hline
\end{tabular}

Table 3. Highest Educational level of the respondents.

\begin{tabular}{ccc}
\hline Highest Educational level & Frequency & Percentage \\
\hline No formal education & 13,900 & 66.1 \\
Primary & 3468 & 16.5 \\
Secondary & 2973 & 14.2 \\
Tertiary & 696 & 3.4 \\
Total & 21,037 & 100.0 \\
\hline
\end{tabular}

Table 4. Current method of family planning used by the respondents.

\begin{tabular}{ccc}
\hline Method of family planning & Frequency & Percentage \\
\hline No method & 19,643 & 93.5 \\
Folkloric method & 86 & 0.4 \\
Traditional method & 187 & 0.9 \\
Modern method & 1121 & 5.3 \\
Total & 21,037 & 100.0 \\
\hline
\end{tabular}

Table 5. Respondents' current marital status.

\begin{tabular}{ccc}
\hline Current marital status & Frequency & Percentage \\
\hline Never in union & 131 & 0.6 \\
Married & 20,357 & 96.7 \\
Living with a partner & 64 & 0.3 \\
Widowed & 159 & 0.8 \\
Divorced & 248 & 1.2 \\
No longer living together/separated & 78 & 0.4 \\
Total & 21,037 & 100.0 \\
\hline
\end{tabular}


Table 6. Respondents' use of modern family planning method by geo-political zone.

\begin{tabular}{cccc}
\hline & \multicolumn{3}{c}{ Family planning method } \\
\cline { 2 - 4 } Geo-political zone & Modern method & Orequency (\%) & Total \\
\cline { 2 - 4 } & $674(14.6)$ & $3940(85.4)$ & $4614(100.0)$ \\
North Central & $211(3.2)$ & $6306(96.8)$ & $6517(100.0)$ \\
North East & $236(2.5)$ & $9670(97.6)$ & $9906(100.0)$ \\
North West & $1121(5.3)$ & $19,916(94.8)$ & $21,037(100.0)$ \\
Total & &
\end{tabular}

Table 7. Odds Ratio for correlates of use of modern family planning Methods among the respondents.

\begin{tabular}{|c|c|c|c|}
\hline \multirow[b]{2}{*}{ Variable } & \multicolumn{2}{|c|}{ Use of modern method of family planning } & \multirow[b]{2}{*}{ p-value } \\
\hline & Odds ratio & $95 \%$ confidence interval & \\
\hline \multicolumn{4}{|l|}{ Education } \\
\hline$\geq$ Secondary school & 3.800 & $3.300125-4.376425$ & $<0.001$ \\
\hline$\leq$ Primary school & 1.000 & & \\
\hline \multicolumn{4}{|l|}{ Age (years) } \\
\hline$\geq 25$ & 1.747 & $1.480726-2.060844$ & $<0.001$ \\
\hline$\leq 24$ & 1.000 & & \\
\hline \multicolumn{4}{|l|}{ Geo-political zone } \\
\hline North-central & 3.926 & $3.435979-4.484965$ & $<0.001$ \\
\hline North-east/North-west & 1.000 & & \\
\hline \multicolumn{4}{|l|}{ Residence } \\
\hline Urban & 2.010 & $1.831593-2.40687$ & $<0.001$ \\
\hline Rural & 1.000 & & \\
\hline \multicolumn{4}{|l|}{ Marital Status } \\
\hline Married & 1.365 & $0.9543387-1.953392$ & 0.088 \\
\hline Others & 1.000 & & \\
\hline
\end{tabular}

(96.77\%) were married, $0.30 \%$ were living with a partner, $0.76 \%$ were widowed, $0.62 \%$ were never in a union, $1.18 \%$ were divorced. Similarly a study in Egypt reported that the most common age group was the $20-29$ years age group who made up $36.4 \%$ of the women studied [4]. In Nnewi, Southeast Nigeria majority (93.6\%) of the women were also married [5]. Similarly in Tanzania majority (92.2\%) of the women were married [6]. Also in India 95.7\% of the women were married [7]. Majority of the women being married in the present study is expected because the average age of the women is $29.5 \pm 7.0$ years and the median age at first marriage for Nigerian women is 18.1 years [8].

Only $5.33 \%$ of the women were currently using modern family planning methods. Interestingly, majority (93.37\%) of the women were not using any method 
of family planning. Traditional method was being practiced by $0.89 \%$ while $0.41 \%$ were practicing folkloric method. This is lower than the prevalence of modern family planning methods reported in Enugu, Southeast Nigeria, where $20 \%$ of the women were using modern family planning methods [9]. It is understandable that the prevalence reported in the Enugu study was higher than the prevalence in our study because Enugu is in the South-eastern region which had a higher prevalence of contraceptive use than the national prevalence as reported in the 2013 Nigerian Demographic and Health Survey [8]. A study reported a prevalence of $12.9 \%$ in Ife Local Government Area (LGA), Southwest, Nigeria and $10.4 \%$ in Jos Local Government Area (LGA), Northcentral Nigeria [10]. These are both higher than the prevalence reported in the present study and this can be explained because Ife is in the Southwest which has the highest prevalence and Jos is in Northcentral which has a higher prevalence than the national prevalence of contraceptive use according to the 2013 Nigerian Demographic and Health Survey [8]. In contrast, a very high prevalence of use of modern family planning was reported in Egypt [4].

In the present study the women who had minimum of secondary education were almost 4 times (3.8 times) more likely than those with only primary education to use modern family planning methods. This agrees with many studies which have demonstrated that education increases the likelihood of using modern family planning methods. A study in the Northwest and Northeast Nigeria reported a statistically significant association between education and use of modern family planning methods [11]. In Bangladesh it was also reported that education increases the use of modern family planning methods [12]. Similarly in Nepal, the practice of modern family planning methods was higher among the educated [13]. In Namibia the educated women studied were 3 times more likely to use modern family planning methods than those who had no formal education [14]. Ainsworth $\mathrm{M}$ et al demonstrated that schooling has a positive relationship with use of modern family planning in 14 Sub-Saharan countries using Demographic and Health Survey data, even after controlling for many other variables [15]. An educated woman is more likely to be aware of the availability of contraceptives. She is also more likely to understand how contraceptives work, hence believe in their efficacy, hence more likely to use modern contraceptives.

In the present study, the older women ( $\geq 25$ years) were 1.7 times more likely than the younger women ( $\leq 24$ years) to use modern family planning methods. This may be because the older women are more likely to be independent minded and financially capable hence more able to procure modern contraceptives. In Bangladesh, age was also a determinant of use of modern family planning methods [12]. Similarly, Awadalla HI demonstrated that the older women in Egypt used modern family planning more than the younger women [4].

In the present study, the women from the Northcentral geopolitical zone were almost 4 times (3.9 times) more likely than those from the other Northern geopolitical zones of the country to use modern family planning methods. This may be because the women in the Northcentral zone have higher educational level 
than their counterparts from the other Northern zones as reported by the 2013 Nigeria Demographic and Health Survey [8].

In the present study, the urban women were twice more likely than the rural women to use modern family planning methods. This is similar to the finding of a study in Egypt which reported that urban women used modern family planning methods more than the rural women [4]. Similarly, Unumeri G et al reported that in the Northeast and Northwest of Nigeria, the urban women used modern family planning methods more than the rural women and the difference was statistically significant [11]. This may be because women in the urban areas are more educated than their counterparts in the rural areas. It could also be because there are more health facilities in the urban areas, hence more access to modern family planning methods.

\section{Conclusion}

In conclusion, the present study has demonstrated that the likelihood of using modern family planning among Northern Nigerian women is increased by the following variables: having at least secondary education; being from the Northcentral zone; being 25 years old or more and urban residence. We therefore recommend the consideration of these factors in the planning of interventions to increase uptake of modern family methods among women in Northern Nigeria. Measures should be taken to increase female literacy especially in the Northeastern and Northwestern zones of Northern Nigeria, as this will most likely lead to improved uptake of family planning among the women of Northern Nigeria.

\section{Acknowledgements}

The authors wish to express gratitude to Measure DHS program for releasing the dataset at no cost to the authors.

\section{Authors' Individual Contributions}

Ikeako L.C., Joe-Ikechebelu N.N. and Nwankwo B.E. conceived of the presented idea and also designed the study. Onyemachi P.E., Chikezie J.C. and Abali I.O. developed the theory and performed the data analysis. Ikeako L.C., Joe-Ikechebelu N.N., Nwankwo B.E., Anene J.O. and Azuike E.D. did the literature review. Anene J.O., Azuike E.D. and Azuike E.C. verified the analytical methods and also wrote up the paper. Azuike E.C. corresponded with the journal. All authors provided critical feedback, discussed the results and contributed to the final manuscript. All authors helped shape the research, and the analysis.

\section{References}

[1] Federal Ministry of Health, Nigeria: Revised National Health Policy Abuja: Federal Ministry of Health 2005, 34-35.

[2] World Health Organisation. Family Planning. www.who.int/mediacentre/factsheets/fs351/en/ 
[3] Measure Evaluation. Demographic and Health Surveys. https://www.measuredhs.com

[4] Awadalla, H.I. (2012) Contraception Use among Egyptian Women: Results from Egypt Demographic and Health Survey in 2005. Journal of Reproduction \& Infertility, 13, 167-173.

[5] Igwegbe, A.O., Ugboaja, J.O. and Monago, E.N. (2009) Prevalence and Determinants of Unmet Needs for Family Planning in Nnewi, Southeast, Nigeria. International Journal of Medicine and Medical Sciences, 9, 325-329.

[6] Kidayi, P.L., Msuya, S., Todd, J., Mtuya, C.C., Mtuy, T. and Mahande, M.J. (2015) Determinants of Modern Contraceptive Use among Women of Reproductive Age in Tanzania: Evidence from Tanzania Demographic and Health Survey Data. Advances in Sexual Medicine, 5, 43-52. https://doi.org/10.4236/asm.2015.53006

[7] Prachi, R., Das, G.S., Ankur, B., Shipra, J. and Binita, K. (2008) A Study of Knowledge, Attitude and Practice of Family Planning among the Women of Reproductive Age Group in Sikkim. The Journal of Obstetrics and Gynecology of India, 58, 63-67.

[8] National Population Commission of Nigeria and ICF International (2014) Nigeria Demographic and Health Survey 2013. Abuja, Nigeria, and Rockville, Maryland, USA: NPC and ICF International, 94.

[9] Onwuzurike, B.K. and Uzochukwu, B.S. (2001) Knowledge, Attitude and Practice of Family Planning amongst Women in a High Density Low Income Urban of Enugu. African Journal of Reproductive Health, 5, 83-89. https://doi.org/10.2307/3583433

[10] Okonofua, F.E., Odimegwu, C., Ajabor, H., Daru, P.H. and Johnson, A. (1999) Assessing the Prevalence and Determinants of Unwanted Pregnancy and Induced Abortion in Nigeria. Studies in Family Planning, 30, 67-77. https://doi.org/10.1111/j.1728-4465.1999.00067.x

[11] Unumeri, G., Ishaku, S., Ahonsi, B. and Oginni, A. (2015) Contraceptive Use and Its Socio-Economic Determinants among Women in Northeast and Northwest Nigeria: A Comparative Analysis. African Population Studies, 9, 1851-1867.

[12] Karmal, S.M. and Islam, A. (2010) Contraceptive Use: Socioeconomic Correlates and Method Choices in Rural Bangladesh. Asia Pacific Journal of Public Health, 22.

[13] Tuladhar, H. and Marahatta, R. (2008) Awareness and Practice of Family Planning Methods in Women Attending Gynae OPD at Nepal Medical College Teaching Hospital. Nepal Medical College Journal, 10, 184-191.

[14] Indongo, N. (2005) Contraceptive Choice and Use of Methods among Young Women in Namibia. Afr. Population Stud, 22, 2.

[15] Ainsworth, M., Beegle, K. and Nyamete, A. (1996) The Impact of Women's Schooling on Fertility and Contraceptive Use: A Study of Fourteen Sub-Saharan African Countries. The World Bank Economic Review, 10, 85-121. https://doi.org/10.1093/wber/10.1.85 